\title{
Determinants of Hip Displacement in Children With Cerebral Palsy
}

\author{
Chia Hsieh Chang MD, Ying Chih Wang MD, Pei Chi Ho MS, \\ Ai Wen Hwang MD, Hsuan Kai Kao MD, Wei Chun Lee MD, \\ Wen E. Yang MD, Ken N. Kuo MD
}

Received: 8 March 2015/Accepted: 10 August 2015/Published online: 20 August 2015

(C) The Association of Bone and Joint Surgeons (B) 2015

\begin{abstract}
Background Coxa valga and femoral anteversion often are seen in patients with spastic hip displacement and osteotomy is recommended. However, the relationship between femoral deformities and hip displacement has not been clearly defined and other factors, such as joint motion and posture, should be considered before recommending treatment.

Questions For children with cerebral palsy with Gross Motor Function Classification System Level IV or V, we

The institution of the author ( $\mathrm{CHC}$ ) has received, during the study period, funding from the Ministry of Science and Technology (Taipei, Taiwan).

Each author certifies that he or she, or a member of his or her immediate family, has no funding or commercial associations (eg, consultancies, stock ownership, equity interest, patent/licensing arrangements, etc) that might pose a conflict of interest in connection with the submitted article.

All ICMJE Conflict of Interest Forms for authors and Clinical Orthopaedics and Related Research ${ }^{\mathbb{R}}$ editors and board members are on file with the publication and can be viewed on request.

Clinical Orthopaedics and Related Research ${ }^{\circledR}$ neither advocates nor endorses the use of any treatment, drug, or device. Readers are encouraged to always seek additional information, including FDA approval status, of any drug or device before clinical use. Each author certifies that his or her institution approved the human protocol for this investigation, and that all investigations were conducted in conformity with ethical principles of research, and that informed consent for participation in the study was obtained. This study was performed at Chang Gung Memorial Hospital, Chang Gung University, Taoyuan, Taiwan.
\end{abstract}

C. H. Chang, Y. C. Wang, P. C. Ho, H. K. Kao, W. C. Lee, W. E. Yang

Department of Pediatric Orthopedics, Bone and Joint Research Center, Chang Gung Memorial Hospital, Chang Gung

University, Taoyuan, Taiwan

A. W. Hwang

Graduate Institute of Early Intervention, College of Medicine,

Chang Gung University, Taoyuan, Taiwan questioned (1) whether hip abduction range correlates with hip displacement, (2) what the relationships are between proximal femoral deformities and hip displacement, and (3) whether the patient with a windblown posture has greater degrees of femoral anteversion?

Methods We retrospectively studied 31 consecutive children with cerebral palsy with Level IV or V gross motor function who underwent three-dimensional CT for preoperative assessment of hip displacement between January 2010 and December 2013. Among the children, 23 had a windblown posture and eight had symmetric hip motion. Femoral anteversion and true neck-shaft angle were measured from the three-dimensional CT images. Migration percentage was the dependent variable we chose to study in relation to femoral anteversion, neck-shaft angle, maximal hip abduction, and hip flexion contracture, using correlations and multiple linear regressions. Using ANOVA and Scheffé's post hoc tests, we analyzed and compared the data of 23 abducted hips and 23 adducted hips in the 23 children with windblown posture and in 16 displaced hips in the eight children with symmetric hip abduction.

Results Greater migration percentage was associated with less hip abduction range $(\mathrm{r}=-0.86 ; \mathrm{p}<0.001)$. Femoral anteversion had a weak correlation $(r=0.28 ; \mathrm{p}<0.05)$ to migration percentage, and the association became insignificant after considering hip abduction motion. Adducted windblown hips had greater femoral anteversion

K. N. Kuo $(\bowtie)$

Department of Orthopedics, National Taiwan University

Hospital, Center for Evidence-Based Medicine, Taipei Medical

University, 250 Wuxing Street, Taipei 11031, Taiwan

e-mail: kennank@aol.com 
than the symmetric displaced hips and abducted windblown hips ( $46^{\circ}$ vs $36^{\circ}$ and $38^{\circ}$, respectively; $\left.\mathrm{p}<0.05\right)$.

Conclusions Our study results did not support a relationship between femoral deformities and hip displacement after considering gross motor function and hip abduction motion. Greater femoral anteversion was noted in the adducted hips of patients with windblown posture, and derotation osteotomy is especially recommended.

Level of Evidence Level III, diagnostic study.

\section{Introduction}

Hip displacement is a common musculoskeletal disorder in patients with cerebral palsy [14, 22, 33], and it may progress to dislocation associated with chronic hip pain and have a negative effect on preexisting motor disability [2, 10]. The goal of treatment for patients with spastic hip displacement has been to restore physiologic biomechanics for hip development; therefore, flexion-adduction contractures and skeletal deformities of the hip often result in surgery for hip displacement [15, 20, 25, 27, 29, 31].

Skeletal deformities in patients with spastic hip displacement include acetabular dysplasia, coxa valga, and excessive femoral anteversion [1, 3, 21, 24, 31]. The degree of acetabular dysplasia has been known to correlate with the migration percentage of hip displacement [6, 9, 17]. With femoral deformities, imbalance of muscle forces and lack of ambulation lead to excessive anteversion and coxa valga that increase with the levels of gross motor function [31]. Laplaza and Root [20] reported increased femoral anteversion had greater correlations than increased coxa valga with hip displacement. Therefore, femoral anteversion should be addressed primarily in surgical management of hip displacement.

Gross Motor Function Classification System levels also have been significantly correlated with incidence of hip displacement [22, 33]. Thus, gross motor function could be a factor in the association between femoral deformities and hip displacement. Without controlling for the moderating effects of gross motor function, the association between femoral deformities and hip displacement cannot be clearly defined. Another problem is that measurement of femoral deformities, as seen on radiographs, could be affected by profound contracture and malposture in children with cerebral palsy who are nonambulatory [8, 16]. With advancements in computerized image processing techniques, three-dimensional (3-D) CT has been proposed as a superior method to measure femoral deformities in children with cerebral palsy $[1,4,7,11,13,18,23,32,34,35]$. Davids et al. [11] reported the accuracy of measuring femoral anteversion was significantly compromised when the femoral models were placed in cerebral palsy alignment (flexion, adduction, and internal rotation), and 3-D assessment was significantly better than two-dimensional assessment.

We used reconstructed 3-D CT to measure the femoral anteversion and neck-shaft valgus angle in children with cerebral palsy with Gross Motor Function Classification System Level IV or V who had hip displacements and different degrees of abduction contractures. We asked (1) whether hip abduction range correlates with hip displacement, (2) what the relationships are between proximal femoral deformities and hip displacement, and (3) if the patient with windblown posture has greater degrees of femoral anteversion.

\section{Patients and Methods}

Children with spastic-type cerebral palsy, who underwent 3-D CT before surgery for hip displacement, with a migration percentage greater than $40 \%$ were the subjects. From January 2010 to December 2014, 35 patients underwent preoperative 3-D CT for hip displacement. Excluding four children with Gross Motor Function Classification System Level II or III, there were 31 (89\%) consecutive patients who were nonambulatory (13 boys and 18 girls). Mean patient age at the time of the imaging study was 8.5 years (range, 4-13 years). All patients had cerebral palsy of Gross Motor Function Classification System Level IV or V. The study was approved by the institutional review board of our hospital.

For the 62 hips studied, available data for each hip included physical examination with angle of hip flexion contracture and angle of maximum hip abduction. Radiographic data for each hip included Reimer's migration percentage [30], femoral anteversion, and neck-shaft angle. Twenty-three children had an apparent windblown posture and eight had symmetric hip abduction, as assessed by one of the authors (CHC). Therefore, we divided the total 62 hips into 23 abducted hips and 23 adducted hips in children with windblown posture and 16 hips in children with symmetric hip motion.

Passive ROM of the hip was measured by one of the authors (CHC) with the patient in the supine position. Flexion contracture of the hip was measured using the Thomas test, in which the flexion angle of the tested hip is measured by a goniometer while the opposite hip is flexed to $130^{\circ}$. Abduction range of the hip, an assessment of adduction contracture, was measured at $90^{\circ}$ hip and knee flexion to prevent confounding owing to flexion contracture. Windblown posture is a habitual asymmetric position of the lower extremities, and in our study it was defined as 

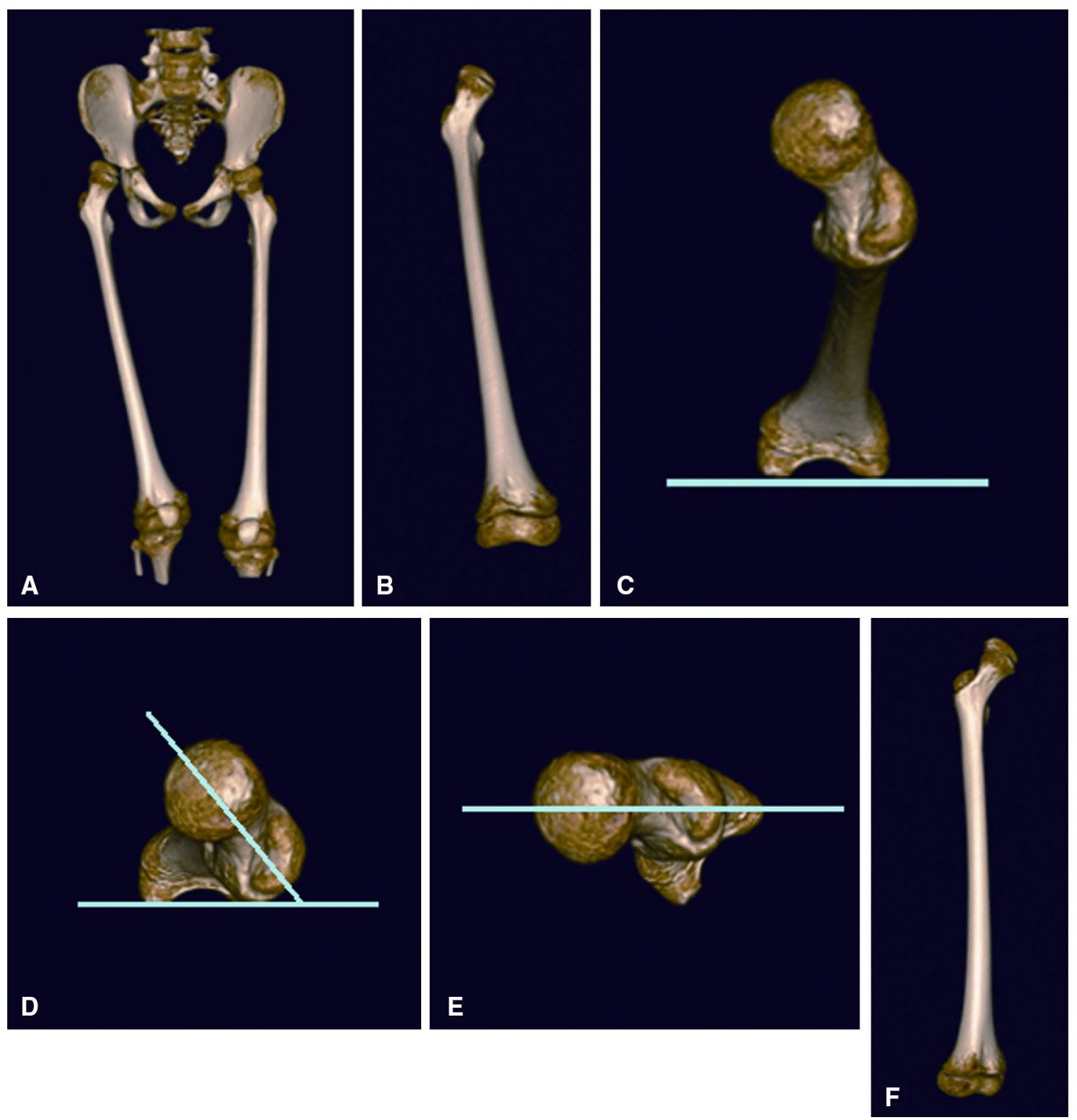

Fig. 1A-F (A) A reconstructed 3-D CT image shows a patient in resting posture. (B) The right femur was isolated for realignment. (C) The two posterior femoral condyles were first aligned horizontally. (D) The posterior tip of the greater trochanter was aligned with the posterior femoral condyles on the same plane to measure the femoral

anteversion angle. (E) To adjust the femoral anteversion, the femur was rotated internally on the transverse plane until the neck axis became horizontal. (F) The femur image was rotated $90^{\circ}$ on the sagittal plane for measuring true neck-shaft angle.

a $20^{\circ}$-discrepancy in the abduction angles of both hips on physical examination.

The migration percentage for the degree of hip displacement was measured, by one of the authors (CHC), on AP radiographs of the pelvis. The migration percentage represented the portion of the ossified femoral head that had migrated laterally beyond the Perkin line, divided by the width of the femoral head $[28,30]$.

The 3-D CT image of the femur was reconstructed and realigned using a standard plane defined by the greater trochanter and two posterior condyles of the femur

(Fig. 1A, B). The image plane was rotated to the horizontal direction, and the femur image was inspected from a cephalic view (Fig. 1C). An anterior inclination line was drawn by connecting the femoral head center and midpoint of the greater trochanter. Femoral anteversion was defined as the angle between the femoral neck anterior inclination line and the line connecting two posterior femoral condyles (Fig. 1D). In measuring the true neck-shaft angle, the femur image was first rotated internally until the anteversion axis was horizontal to correct anteversion (Fig. 1E). The femur image then was rotated $90^{\circ}$ on the sagittal plane 
to view the true neck-shaft angle. The true neck-shaft angle was measured as the angle between the longitudinal axis of the femoral shaft and the axial line of the femoral neck [36] (Fig. 1F). The 3-D CT measurement was performed by one of the authors $(\mathrm{PCH})$.

Validation of realignment and measurement of femoral anteversion and neck-shaft angle were performed with CT, using two standard sawbones models of the femur (Pacific Research Laboratories, Vashon, WA, USA). One sawbones model was placed in the neutral position and the other was placed in the flexion-adduction position in the CT scanner to test the influence from malposture usually seen in children with cerebral palsy. The commercial femur model has a neck-shaft angle of $137^{\circ}$ and femoral anteversion of $12^{\circ}$. The neck-shaft angle and femoral anteversion measured from 3-D CT images were $135^{\circ}$ and $13^{\circ}$, respectively. No difference was seen when a sawbones femur was used to simulate neutral position or in the flexion-adduction position.

Reliability of the measurements was tested by randomly choosing 30 hips in 15 patients. Two investigators (YCW, $\mathrm{PCH})$ realigned images and measured femoral anteversion and neck-shaft angle independently. Intrarater reliability was tested by measuring images twice, 2 weeks apart. Measurement of the femoral anteversion had good intraand interrater reliabilities, with intraclass correlation coefficients of 0.96 and 0.84 . Measurement of the neckshaft angle also had good intra- and interrater reliabilities, with intraclass correlation coefficients of 0.89 and 0.82 .

For our first two questions, migration percentage was the dependent variable, and hip abduction range, flexion contracture, femoral anteversion, and neck-shaft angle were independent variables. Pearson's correlation was used to test the relationship between migration percentage and each independent variable. Then multiple linear regressions were used to remove the confounding among independent variables.

For our third question, the 62 hips were classified as adducted windblown hips, abducted windblown hips, or symmetric displaced hips by patient posture. The means of the hip motion (flexion contracture, abduction) and radiographic measures (migration percentage, femoral anteversion, neck-shaft angle) were compared across the three groups of hips using ANOVA with Scheffé's post hoc tests. Analyses were completed using SPSS software, version 17.0 (SPSS, Inc, Chicago, IL, USA), and a p value less than 0.05 was regarded as significant.

\section{Results}

For questions 1 and 2, greater migration percentage was associated with less hip abduction range $(\mathrm{r}=-0.83$; $\mathrm{p}<$
0.001). Femoral anteversion had a weak correlation ( $\mathrm{r}=$ $0.28 ; \mathrm{p}<0.05)$ to migration percentage. With the numbers available, hip flexion contracture or neck-shaft angle was not associated with migration percentage. After controlling for relevant confounding variables by regression, only abduction range was associated with hip migration percentage $\left(R^{2}=0.68 ; p<0.05\right)$. The significant correlation between femoral anteversion and migration percentage was completely explained by abduction range. The effect from abduction range in the association between femoral anteversion and migration percentage was shown by scatter plots of the 62 hips. The association was no longer significant after considering abduction range (Fig. 2).
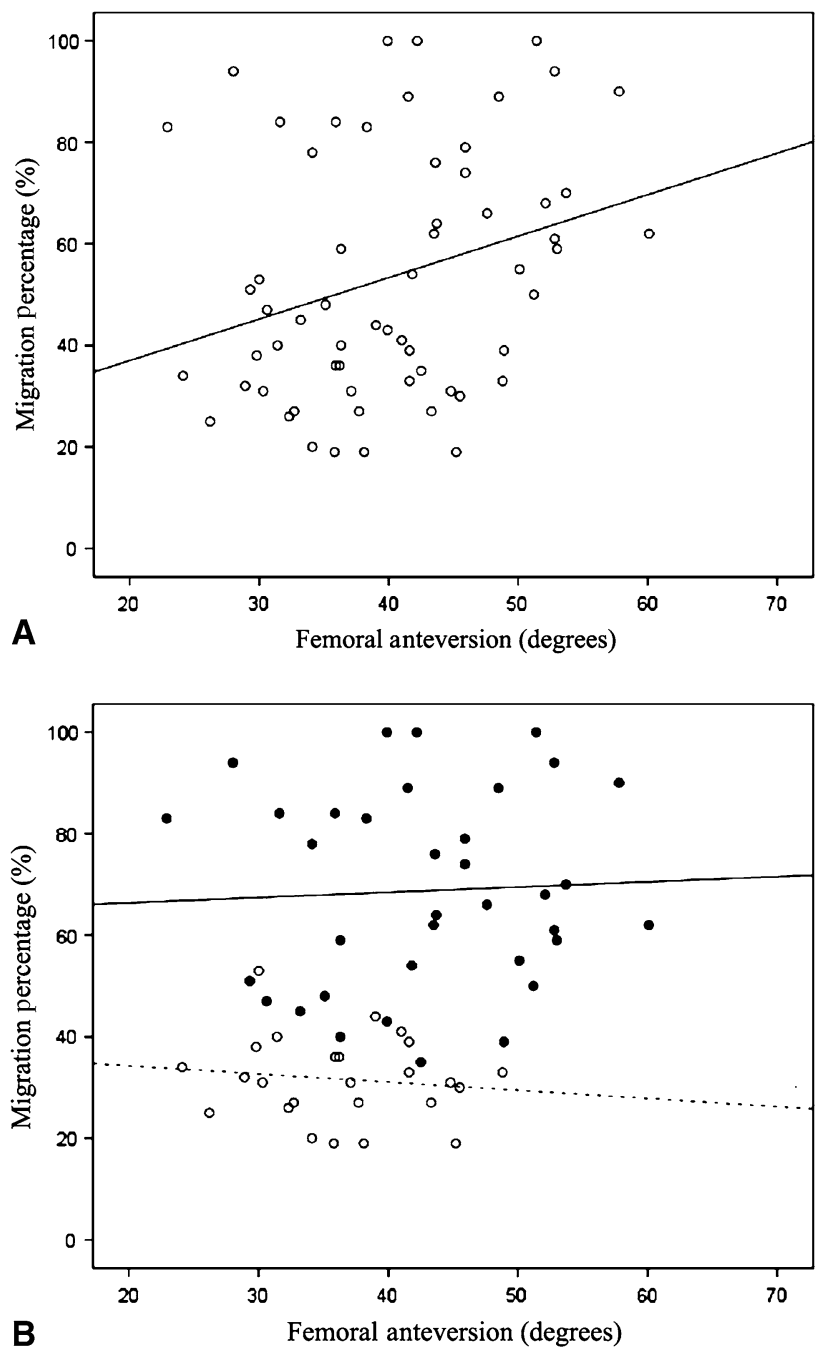

Fig. 2A-B (A) A scatter plot shows femoral anteversion and migration percentage relationship of the 62 hips included in our study. A regression line shows a weak association between femoral anteversion and migration percentage $\left(r^{2}=0.084 ; p=0.023\right)$. (B) After grouping the 62 hips into hips with abduction greater than $40^{\circ}$ (๑) and hips with abduction less than $40^{\circ}(\bigcirc)$ by a simple cut-off value, the association between femoral anteversion and migration percentage became nonsignificant. 
Table 1. Means and standard deviations of hip motions and radiographic measurements in the three groups of hips

\begin{tabular}{|c|c|c|c|c|c|}
\hline Group & $\begin{array}{l}\text { Hip abduction } \\
\text { angle* Mean (SD) }\end{array}$ & $\begin{array}{l}\text { Hip flexion } \\
\text { contracture } \\
\text { Mean (SD) }\end{array}$ & $\begin{array}{l}\text { Migration percentage* } \\
\text { Mean (SD) }\end{array}$ & $\begin{array}{l}\text { Femoral anteversion* } \\
\text { Mean (SD) }\end{array}$ & $\begin{array}{l}\text { Neck-shaft } \\
\text { angle Mean } \\
\text { (SD) }\end{array}$ \\
\hline $\begin{array}{l}23 \text { hips in the abduction sides of } \\
\text { windblown posture }\end{array}$ & $\begin{array}{l}50.4^{\circ} \\
\left(6.0^{\circ}\right)\end{array}$ & $\begin{array}{l}12.8^{\circ} \\
\left(10.5^{\circ}\right)\end{array}$ & $\begin{array}{l}30.6 \% \\
(7.3 \%)\end{array}$ & $\begin{array}{l}38.3^{\circ} \\
\left(6.7^{\circ}\right)\end{array}$ & $\begin{array}{l}147.2^{\circ} \\
\left(8.5^{\circ}\right)\end{array}$ \\
\hline $\begin{array}{l}23 \text { hips in the adduction sides of } \\
\text { windblown posture }\end{array}$ & $\begin{array}{l}21.3^{\circ} \\
\left(9.8^{\circ}\right)\end{array}$ & $\begin{array}{l}13.9^{\circ} \\
\left(9.3^{\circ}\right)\end{array}$ & $\begin{array}{l}67.6 \% \\
(16.5 \%)\end{array}$ & $\begin{array}{l}45.9^{\circ} \\
\left(7.1^{\circ}\right)\end{array}$ & $\begin{array}{l}143.8^{\circ} \\
\left(8.3^{\circ}\right)\end{array}$ \\
\hline $\begin{array}{l}16 \text { bilateral displaced hips } \\
\text { without windblown posture }\end{array}$ & $\begin{array}{l}31.9^{\circ} \\
\left(11.5^{\circ}\right)\end{array}$ & $\begin{array}{l}18.1^{\circ} \\
\left(8.3^{\circ}\right)\end{array}$ & $\begin{array}{l}66.0 \% \\
(24.2 \%)\end{array}$ & $\begin{array}{l}35.5^{\circ} \\
\left(9.3^{\circ}\right)\end{array}$ & $\begin{array}{l}146.9^{\circ} \\
\left(4.3^{\circ}\right)\end{array}$ \\
\hline $\begin{array}{l}\text { Significant difference in } \\
\text { post hoc analysis }\end{array}$ & $\begin{array}{l}\text { Abduction vs } \\
\text { adduction; } \\
\text { abduction vs bilateral } \\
\text { displaced; } \\
\text { adduction vs bilateral } \\
\text { displaced }\end{array}$ & & $\begin{array}{l}\text { Abduction vs } \\
\text { adduction; } \\
\text { abduction vs } \\
\text { bilateral displaced }\end{array}$ & $\begin{array}{l}\text { Adduction vs } \\
\text { abduction; } \\
\text { adduction vs bilateral } \\
\text { displaced }\end{array}$ & \\
\hline
\end{tabular}

$* \mathrm{p}<0.05$ in comparison across three groups using ANOVA.

For our third question, ANOVA revealed that abduction range, migration percentage, and femoral anteversion were significantly different among the three groups of hips. Post hoc testing revealed that the adducted windblown hips had the greatest femoral anteversion of $46^{\circ}$. Symmetric displaced hips and abducted windblown hips had similar femoral anteversion $\left(36^{\circ}\right.$ vs $\left.38^{\circ} ; \mathrm{p}=0.31\right)$, although symmetric displaced hips had a greater migration percentage than abducted windblown hips (66\% vs $31 \%$; $p<$ 0.001) (Table 1).

\section{Discussion}

Measuring femoral anteversion and coxa valga in children with cerebral palsy who are nonambulatory is a clinical dilemma. The measurements often are confounded by soft tissue contracture and profound bone deformities [11,26], yet hip displacement most likely occurs in children with cerebral palsy who are nonambulatory and requires accurate measurements for therapeutic decision-making. With advancements in imaging techniques, we found that excessive femoral anteversion was associated with adducted side of windblown posture and was not related to the percentage of hip displacement. Neck-shaft angle was generally high in children with cerebral palsy who had Level IV or V gross motor function, and neck-shaft angle was not associated with hip displacement or posture. The study results did not support femoral deformities as factors for hip displacement in children with cerebral palsy who are nonambulatory, and other factors were involved in the deteriorating course from a nondisplaced hip to a dislocated hip.

There are limitations to our study. First, it is a crosssectional study that supports the association between existing factors rather than a causal relationship. Second, we had a small sample size that prevented further analysis of the effects of age stratum and there is not enough power to detect small-to-medium sized differences if they existed. Third, only children with cerebral palsy who were nonambulatory were included, and the effects of posture on skeletal deformities in children who were ambulatory were not observed. Fourth, because of ethical concerns regarding radiation exposure from 3-D CT of the pelvis, the study did not include children without hip displacement with Gross Motor Function Classification System Level IV or V or those did not require surgical intervention to conduct a thorough analysis.

Gross motor function and hip abduction motion are strong global risk factors for spastic hip displacement, and they have been associated with femoral deformities $[5,22$, $31,33]$. In the relationships among motor function, hip abduction, femoral deformity, and hip displacement, femoral deformity is a proxy factor of the two strong risk factors and is associated with hip displacement [19]. For example, a child with cerebral palsy with Gross Motor Function Classification System Level I has minimal risk of hip displacement and femoral deformities, whereas a child with cerebral palsy with Gross Motor Function Classification System Level $\mathrm{V}$ has the greatest risk of hip displacement and femoral deformities. When children with cerebral palsy with Gross Motor Function Classification System Level I to Level V are studied together, femoral anteversion could be associated with hip displacement by the interaction of gross motor function.

Femoral anteversion decreases gradually from $40^{\circ}$ at birth to $15^{\circ}$ at skeletal maturity in children who do not have cerebral palsy or other causes of hip dysplasia $[5,12]$. The natural decrease in anteversion angle was interrupted by 
neurologic disorders and lack of normal physiologic stress in children with cerebral palsy. Our study revealed an effect of windblown posture on femoral anteversion. Greater femoral anteversion of $46^{\circ}$ was seen in the adducted hips of children with cerebral palsy with windblown posture. We speculate that an additional effect from chronic adduction and internal rotation stress on the femoral head might cause excessive femoral anteversion.

Our study results do not support an association between femoral deformities and hip displacement in children with cerebral palsy and Gross Motor Function Classification System Level IV or V function. Coxa valga and excessive femoral anteversion generally were found in children with cerebral palsy who were nonambulatory, regardless whether hip displacement was present. Soft tissue factors probably are more important in hip displacement, whereas proximal femur deformities are secondary. For preventing hip displacement, our study results supported treatment to release flexion-adduction contracture and balance windblown posture. Femoral derotation osteotomy is especially indicated for the adducted hips in children with windblown posture.

\section{References}

1. Abel MF, Sutherland DH, Wenger DR, Mubarak SJ. Evaluation of CT scans and 3-D reformatted images for quantitative assessment of the hip. J Pediatr Orthop.1994;14:48-53.

2. Bagg MR, Farber J, Miller F. Long-term follow-up of hip subluxation in cerebral palsy patients. J Pediatr Orthop. 1993;13:3236.

3. Beals RK. Developmental changes in the femur and acetabulum in spastic paraplegia and diplegia. Dev Med Child Neurol. 1969;11:303-313.

4. Berman L, Mitchell R, Katz D. Ultrasound assessment of femoral anteversion: a comparison with computerised tomography. $J$ Bone Joint Surg Br. 1987;69:268-270.

5. Bobroff ED, Chambers HG, Sartoris DJ, Wyatt MP, Sutherland DH. Femoral anteversion and neck-shaft angle in children with cerebral palsy. Clin Orthop Relat Res. 1999;364:194-204.

6. Chang CH, Kuo KN, Wang CJ, Chen YY, Cheng HY, Kao HK. Acetabular deficiency in spastic hip subluxation. J Pediatr Orthop. 2011;31:648-654.

7. Cherney DL, Westin GW. Acetabular development in the infant's dislocated hips. Clin Orthop Relat Res.1989;242:98-103.

8. Chung CY, Lee KM, Park MS, Lee SH, Choi IH, Cho TJ. Validity and reliability of measuring femoral anteversion and neck-shaft angle in patients with cerebral palsy. J Bone Joint Surg Am. 2010; 92:1195-1205.

9. Chung CY, Park MS, Choi IH, Cho TJ, Yoo WJ, Lee KM. Morphometric analysis of acetabular dysplasia in cerebral palsy. J Bone Joint Surg Br. 2006;88:243-247.

10. Cooperman DR, Bartucci E, Dietrick E, Millar EA. Hip dislocation in spastic cerebral palsy: long-term consequences. $J$ Pediatr Orthop. 1987;7:268-276.

11. Davids JR, Marshall AD, Blocker ER, Frick SL, Blackhurst DW, Skewes E. Femoral anteversion in children with cerebral palsy: assessment with two and three-dimensional computed tomography scans. J Bone Joint Surg Am. 2003;85:481-488.
12. Fabry G, MacEwen GD, Shands AR Jr. Torsion of the femur: a follow-up study in normal and abnormal conditions. J Bone Joint Surg Am. 1973;55:1726-1738.

13. Gose S, Sakai T, Shibata T, Murase T, Yoshikawa H, Sugamoto $\mathrm{K}$. Morphometric analysis of the femur in cerebral palsy: 3-dimensional CT study. J Pediatr Orthop. 2010;30:568-574.

14. Hägglund G, Lauge-Pedersen $\mathrm{H}$, Wagner P. Characteristics of children with hip displacement in cerebral palsy. BMC Musculoskelet Disord. 2007;8:101.

15. Herndon WA, Bolano L, Sullivan JA. Hip stabilization in severely involved cerebral palsy patients. J Pediatr Orthop. 1992;12:68-73.

16. Kay RM, Jaki KA, Skaggs DL. The effect of femoral rotation on the projected femoral neck-shaft angle. J Pediatr Orthop. 2000;20:736-739.

17. Kim HT, Wenger DR. Location of acetabular deficiency and associated hip dislocation in neuromuscular hip dysplasia: threedimensional computed tomographic analysis. J Pediatr Orthop. 1997; 17:143-151.

18. Kim JS, Park TS, Park SB, Kim JS, Kim IY, Kim SI. Measurement of femoral neck anteversion in 3D. Part 1: 3D imaging method. Med Biol Eng Comput. 2000; 38:603-609.

19. Kraemer HC, Stice E, Kazdin A, Offord D, Kupfer D. How do risk factors work together? Mediators, moderators, and independent, overlapping, and proxy risk factors. Am J Psychiatry. 2001;158:848-856.

20. Laplaza FJ, Root L. Femoral anteversion and neck-shaft angles in hip instability in cerebral palsy. J Pediatr Orthop. 1994;14:719723.

21. Laplaza FJ, Root L, Tassanawipas A, Glasser DB. Femoral torsion and neck-shaft angles in cerebral palsy. J Pediatr Orthop. 1993;13:192-199.

22. Larnert $P$, Risto $O$, Hägglund $G$, Wagner P. Hip displacement in relation to age and gross motor function in children with cerebral palsy. J Child Orthop. 2014;8:129-134.

23. Lausten GS, Jørgensen F, Boesen J. Measurement of anteversion of the femoral neck: ultrasound and computerised tomography compared. J Bone Joint Surg Br.1989;71:237-239.

24. Lewis FR, Samilson RR, Lucas DB. Femoral torsion and coxa valga in cerebral palsy: a preliminary report. Dev Med Child Neurol. 1964;6:591-597.

25. Miller F, Girardi H, Lipton G, Ponzio R, Klaumann M, Dabney $\mathrm{KW}$. Reconstruction of the dysplastic spastic hip with peri-ilial pelvic and femoral osteotomy followed by immediate mobilization. J Pediatr Orthop .1997;17:592-602.

26. Miller F, Liang Y, Merlo M, Harcke HT. Measuring anteversion and femoral neck-shaft angle in cerebral palsy. Dev Med Child Neurol. 1997;39:113-118.

27. Noonan KJ, Walker TL, Kayes KJ, Feinberg J. Varus derotation osteotomy for the treatment of hip subluxation and dislocation in cerebral palsy: statistical analysis in 73 hips. J Pediatr Orthop B. 2001;10:279-286.

28. Parrott J, Boyd RN, Dobson F, Lancaster A, Love S, Oates J, Wolfe R, Nattrass GR, Graham HK. Hip displacement in spastic cerebral palsy: repeatability of radiologic measurement. J Pediatr Orthop. 2002;22:660-667.

29. Presedo A, Oh CW, Dabney KW, Miller F.Soft-tissue releases to treat spastic hip subluxation in children with cerebral palsy. $J$ Bone Joint Surg Am. 2005;87:832-841.

30. Reimers J. The stability of the hip in children: a radiological study of the results of muscle surgery in cerebral palsy. Acta Orthop Scand Suppl. 1980;184:1-100.

31. Robin J, Graham HK, Selber P, Dobson F, Smith K, Baker R. Proximal femoral geometry in cerebral palsy: a population-based cross-sectional study. J Bone Joint Surg Br. 2008;90:1372-1379. 
32. Ruwe PA, Gage JR, Ozonoff MB, DeLuca PA. Clinical determination of femoral anteversion: a comparison with established techniques. J Bone Joint Surg Am. 1992;74:820-830.

33. Soo B, Howard JJ, Boyd RN, Reid SM, Lanigan A, Wolfe R, Reddihough D, Graham HK. Hip displacement in cerebral palsy. J Bone Joint Surg Am. 2006;88:121-129.

34. Sugano N, Noble PC, Kamaric E. A comparison of alternative methods of measuring femoral anteversion. J Comput Assist Tomogr. 1998;22:610-614.
35. Tomczak RJ, Guenther KP, Rieber A, Mergo P, Ros PR, Brambs HJ. MR imaging measurement of the femoral antetorsional angle as a new technique: comparison with $\mathrm{CT}$ in children and adults. AJR Am J Roentgenol. 1997;168:791-794.

36. Wang YC, Li WC, Kao HK, Yang WE, Chang CH. Deformities of proximal femur in spastic hip displacement: a reconstructed three-dimensional computed tomography model approach. Formosan J Musculoskelet Disord. 2013;4:38-41. 